\title{
PAUL RICCEUR: la imposibilidad de un saber sin supuestos
}

\section{PAUL RICGUR: the impossibility of knowledge without assumptions}

\author{
Gabriel Ocampo Sepúlveda; Laura Mireya Cardona
}

Cómo citar: Ocampo,G \& Cardona L.M(2015). Paul Ricceur: la imposibilidad de un saber sin supuestos. Inciso n 17: 177-191

Recibido: 15/02/2015|Revisado: 20/04/2015|Aceptado: 10/12/2015

\section{Resumen}

El presente escrito hace una aproximación reflexiva a la posición de Paul Ricœur en torno al problema de la objetividad y la subjetividad en la investigación en ciencias sociales y sus implicaciones en el ámbito político, ético, moral y legal. Efectivamente, el filósofo francés al considerar el discurso político como frágil y falible, no deja de llamar la atención sobre las pretensiones cientificistas de la llamada "ciencia", sus científicos y sus expertos. Advierte que no dejaría de ocultarse, en realidad, una particular visión del mundo que se pretende imponer como única y absoluta y es, por tanto, que aboga por una actitud crítica y reflexiva que promueva el disenso; e, como bien se puede inferir del pensamiento de Ricœur, la credibilidad y legitimidad de cualquier autoridad depende, en parte, de la existencia de espacios para que las voces críticas puedan ser escuchadas y respondidas; por el contrario, sin esos espacios, la credibilidad de la autoridad se encuentra minada. En efecto, todo Estado democrático necesita una sociedad civil fuerte y ello se tiene que hacer más claro en los asuntos de la educación, la legitimidad y la ley.

Palabras clave: sujeto, objeto, ciencia, cientifismo, crítica

\begin{abstract}
This essay approaches reflexively Paul Ricœur's point of view on objectivity and subjectivity within social science research and its implications on the field of politics, ethics, morality and legality. In fact, the French philosopher by considering political discourse as very fragile and fallible, calls our attention over many scientistic pretentions of the so called "science", its Scientifics and experts. For him, those claims hide in fact a particular worldview to be imposed as the sole and absolute and that is why Ricœur calls for a reflexive and critical attitude to encourage dissent. As you can infer from Ricœur's thought, the credibility of the authority depends, partly, on the existence of spaces for critical voices could be heard and answered; otherwise, without such spaces, the credibility of the authority would be undermined. He believes that every democratic State must need a strong and healthy civil society and that fact is more evident in issues such as education, law and legitimacy.
\end{abstract}

Key words: subject, object, science, scientism, critic.

\footnotetext{
* Este escrito se constituye en un avance de investigación en su etapa de exploración y fundamentación del proyecto 708 titulado "El estatuto de la ética ambiental como ética aplicada. Universidad del Quindío.

**Profesor en la Universidad del Quindío desde febrero de 1996. Doctor en Filosofía de la Pontificia Universidad Javeriana-Bogotá (2014), Magíster en Filosofía de la Pontificia Universidad Javeriana-Bogotá (2005), Filósofo de la Universidad del Quindío (2000), Licenciado en Lenguas Modernas de la Universidad del Quindío (1994), Músico de la Bill Collis School, Londres, Inglaterra (1990) y estudios en Inglés y Francés de la Universidad de Cambridge, Inglaterra (1990). Investigador del Grupo de Investigación en filosofía política, social y jurídica: POLITIA -Universidad del Quindío. gabriel.os9@gmail.com, Colombia. *** Profesora en la Universidad del Quindío desde febrero de 2011. Candidata a Magíster en Filosofía de la Pontificia Universidad Javeriana-Bogotá, Filósofa de la Universidad del Quindío (2000), Investigadora del Grupo de Investigación en filosofía política, social y jurídica: POLITIA -Universidad del Quindío. laurismct@hotmail.com. Colombia
} 


\section{Introducción}

El presente escrito ha de buscar hacer unas reflexiones sobre la posición de Paul Ricœur en torno al problema de la objetividad y la subjetividad en la investigación en ciencias sociales, cuestión que exige preguntarse por el estatus de cientificidad de estas últimas y por tanto, sobre su coherencia y cohesión, así como sus consecuencias en el ámbito ético, político y moral.

Este ejercicio exegético sobre el pensamiento del filósofo francés, no deja de ser un paso previo, y que se considera acá "necesario", para abordar una serie de importantes temas y problemáticas en relación con el conocimiento, sus implicaciones éticas, políticas y sociales, pero, antes que nada, sobre la posibilidad de articular una ética ambiental en clave hermenéutica. No se puede dejar de confesar que este escrito es un ejercicio de "escribiendo-pensando", es decir, lo acá presentado no se llega a constituir en un "informe de resultados", más bien, se aprovecha la oportunidad de escribir como el proceso investigativo mismo. En consecuencia, debemos advertir al lector que a continuación no se va a encontrar un sistema cerrado, una esfera perfecta o un bloque completamente cohesionado en sus diferentes partes, por el contrario, habrá fuertes remolinos, sobresaltos, cambios de altitud y de clima y sobretodo, de tensiones y grietas aparentemente, insalvables.

En este punto debe quedar claro que el hecho de pretender asumir una postura crítica ante el cientificismo no tendría por qué considerarse como una ataque a la ciencia como tal, sino que la apuesta no llega a ser otra que hacer evidente que, detrás de las pretensiones cientificistas (una ciencia caricaturizada o desdibujada) de la hoy llamada "ciencia", sus científicos y sus expertos, no dejaría de ocultarse en realidad una particular visión del mundo que se pretende imponer como única y absoluta y que, en cierto sentido, nos llevará al llamado de atención de Ricœur a que las personas se apropien de la gran responsabilidad que les compete como ciudadanos de buscar preservar los espacios que propician el disenso.

En efecto, estos primeros pasos de la investigación sobre la posibilidad de una ética ambiental hermenéutica nos ha de llevar, en primera instancia, a transitar a través del debate epistemológico; en segunda instancia, a buscar alcanzar el ámbito del discurso utópico e ideológico y sus relaciones con el discurso y el poder; y, finalmente, a cotejar las anteriores relaciones con la fragilidad de la política.

\section{Algunos apuntes sobre la hermenéutica fenomenológica de Ricœur}

Cabe señalar que antes de abordar la discusión, se encuentra la necesidad de hacer una breve presentación de la filosofía del filósofo francés.

Como bien se sabe, Paul Ricœur es considerado el precursor de la articulación de la fenomenología y la hermenéutica como un modelo de nuevo cuño de la filosofía de la reflexión, enmarcada en la tradición fenomenológica francesa de Emmanuel Levinas y Merleau- Ponty, la fenomenología de Husserl y Scheler, el existencialismo de Jaspers y Marcel y el personalismo de E. Mounier.

Se debe resaltar que los análisis filosóficos de Ricœur buscan identificar el ser del yo propendiendo por superar el marco tradicional del sujeto cognoscente como un ámbito de conocimiento objetivo y de la experiencia sensible para abarcar la acción y la libertad (Dauenhauer, 1998). La posición fundamental de la hermenéutica fenomenológica ricœuriana no es otra que el reconocimiento de las condiciones históricas que hacen que todo conocimiento humano se encuentre subsumido en el ámbito de la finitud. Para Ricœur, los sujetos no crean sentido ex nihilo sino que surgen de, y se hallan continuamente influenciados por las historias sociales y las tradiciones culturales y artísticas. Es decir, ya hay siempre algo que los precede, un material sobre el cual constituirse como agentes morales, políticos y de comprensión. Así pues, su hermenéutica se caracteriza por el intento sistemático de alcanzar posibles conclusiones a la aceptación de esta inevitable finitud del entendimiento humano. Esto significa la imposibilidad de una ciencia en el sentido tradicional del término, de la existencia o del ser, más aún, la imposibilidad, por no decir, la no deseabilidad, de una ciencia de la ética. Lo anterior justifica su cuestionamiento del objetivismo positivista y su propensión a sostener la vana y malsana pretensión 
por alcanzar la interpretación correcta y definitiva de un texto, de las acciones humanas, de las realidades culturales, las instituciones, etc., o de cualquier otro producto humano. Efectivamente, su hermenéutica se constituye en "una hermenéutica de la finitud".

No de otra forma, al poner en entredicho la oposición moderna entre lo "real" y lo "imaginario"- Ricœur muestra la forma cómo la verdad hermenéutica llega a ser el resultado de la imaginación productiva que, como imaginación poética (el medio a través del cual el "mundo del texto" o "el referente de segundo orden" obtienen su existencia) se constituye en una fuerza subversiva frente a lo que es comúnmente o tradicionalmente tomado como "real". Este énfasis busca evitar que la hermenéutica caiga en una tendencia "conservadora" y por tanto, como una "hermenéutica de la potencia-de-ser" (una crítica a las ilusiones y a la falsa conciencia del sujeto) pueda ofrecer una crítica a discursos manipuladores. Un tema recurrente en sus análisis ha sido el de los imaginarios sociales, en otras palabras, la institución imaginaria de la sociedad; este interés testifica su intensa preocupación por la filosofía política, social, ética y moral.

Así pues, como una variante hermenéutica de la fenomenología, desde un comienzo, ha rechazado tajantemente uno de los presupuestos fundamentales de esta: el acceso inmediato a sí y al sentido ${ }^{l}$. Es así que su hermenéutica fenomenológica exige un extenso giro por la interpretación de las producciones objetivas de los sujetos, ya que, considera con Van den Hengel que: "El sentido de la experiencia humana se hace a través de nosotros y no somos nosotros los que le damos sentido. No somos los que dominamos el

1. En relación con esta tradición, Ricœur sostendría siempre la tesis de que la filosofía invariablemente comporta un momento reflexivo, es decir, el regreso al sujeto sobre sí mismo, una búsqueda de una reapropiación de sí; según esto, él siempre habrá de separar el método reflexivo de la afirmación orgullosa -de corte idealista o en todo caso subjetivista- del primado de la conciencia. La conciencia para Ricœur no es el origen ni el fundamento sino una tarea, esta no es transparente sino más bien opaca, ella exige un esfuerzo constante de dilucidación, de unificación con el fin de recuperar el esfuerzo o el deseo de existir que se expresa en la multiplicidad de operaciones del sujeto y de los signos a través de los cuales estas operaciones se objetivan. Esa será la razón por lo que concierne a la fenomenología husserliana que Ricœur no dejará de ver el método fenomenológico como un recurso de valor inestimable para dar cuenta de los fenómenos en toda su riqueza: él mantendría siempre sus reservas frente a los desarrollos idealistas presentados en el Husserl maduro. Después, Ricœur, con su enfoque fenomenológico, encontraría los elementos para conducir una dinámica fértil que condujera la fenomenología más allá del idealismo, dentro de la fidelidad al rigor de la interrogación y a lo que él consideraba como el descubrimiento más importante de Husserl, a saber, la intencionalidad de la conciencia. sentido, sino que, más bien, el sentido nos constituye a la vez que buscamos interpretarlo" (Hengel, 1982: 107).

De tal suerte, a diferencia de toda una serie de posturas filosóficas contemporáneas que han optado por una u otra vía en relación con la figura del sujeto heredada de la modernidad, la hermenéutica del hombre capaz ricœuriana ha logrado articular una opción que le ha permitido salir de la situación paradójica de tener que elegir entre un cogito exaltado (Descartes, Kant, Husserl) o un cogito humillado (Nietzsche) porque le ha posibilitado, a través del lenguaje, un acceso mediado a la ipseidad de sí y ello, a través de la: "Mediación por los signos, por los símbolos, por los textos pero, también, en el orden de la acción, de la capacidad de hacer del agente" (Ricoeur, 2006:37). Así, a diferencia de otras formas de pensamiento postmoderno y contemporáneo, por medio de esta propuesta hermenéutica ha buscado evitar la tentación de exaltar "la muerte del hombre" y, de tal suerte, no se ha sumado a aquellos que han clamado por la eliminación del "sujeto".

Al respecto, ha insistido constantemente en no abandonarlanocióndesujeto-noobstante, nohadejado de aceptar la necesidad de purgarla de sus vínculos metafísicos provenientes de la modernidad. Es decir, se ha aferrado a una motivación fundamentalmente existencial en oposición al objetivismo cientificista-fisicalista al concebir su propuesta hermenéutica como una herramienta metodológica, por medio de la cual el sujeto reflexivo ha de poder acceder a la comprensión "del deseo de ser y el esfuerzo por existir que nos constituye". Desde su punto de vista, el fin último de toda comprensión no podría ser otro que la comprensión de sí que trae consigo una transformación de sí por medio del lenguaje. E insiste en que, el intento del sujeto de la reflexión no es otro que comprender su deseo de ser -el conatus, la energeia, la vida. En ese caso, siempre ha presupuesto una proximidad básica entre el deseo y el habla. Así pues, al final del proceso, la comprensión no deviene solamente en una forma de comprensión de sí, sino que toda auto-comprensión se constituye, finalmente, en un asunto de transformación crítica de sí. 
De tal manera, el hombre, en cuanto agente, se ha de entender como el devenir constante de una oposición establecida entre el horizonte de felicidad (afirmación originaria) y la perspectiva sedimentada y estratificada de su carácter (diferencia existencial). Es esta desproporción práctica la que lleva al agente a actuar y a transformar el mundo y, a la vez, se sedimenta en el agente inscribiendo el horizonte de felicidad en su carácter concreto y singular. En tal sentido, en ese constante devenir de la existencia práctica del hombre, el agente se edifica a sí mismo en la misma medida en que transforma el mundo. (Casarotti, 2008:401).

En consecuencia, el objetivo ético de los individuos, será siempre -para Ricœur-, el de: "Pretender una vida buena, con y por los otros, en medio de instituciones justas", Su "pequeña ética", como él mismo la denomina, se propone, entonces, ofrecer la herramientas suficientes para que cada cual busque: "Hacer de la historia de su vida una buena historia", (Simms, 1995: 2) o a la manera socrática, que cada cual haga de su vida, una historia que haya valido la pena ser vivida por haber sido siempre objeto de examen crítico. O, en palabras de Ricœur: "Aquello que exige examen es pues la vida, la manera de conducir nuestra vida" (Ricoeur, 1995: 16).

\section{La relación sujeto-objeto: ciencias naturales vs ciencias humanas}

Como bien se planteó con anterioridad, antes de entrar a considerar el análisis ricœuriano sobre la objetividad, la subjetividad y sus múltiples implicaciones, se hace necesaria una aclaración sucinta sobre diferentes formas y particularidades que toma la investigación en ciencias sociales a la luz de las ciencias naturales.

Puede decirse que desde la antigua Grecia -con Platón y Aristóteles- hasta nuestros días, dos grandes vertientes o corrientes han estado en disputa acerca de cómo acceder al y generar el conocimiento científico: el empirismo, de base aristotélica, y el racionalismo, de base platónica (Mardones, 1991). Sin embargo, con los estudios de Jean Piaget (1896-1980) se va gestando una tercera vertiente, la dialéctica, que como una especie de síntesis propone una reorientación de la relación $\mathrm{S}-\mathrm{O}$ (sujeto-objeto) al concebir una interacción mutua y en constante movimiento entre los dos elementos de la relación: sujeto cognoscente y objeto de conocimiento. Es pues, en este contexto de confrontación entre estas tres vertientes (racionalismo, empirismo y dialéctica) donde se han llegado a gestar unas ciencias sociales -o del hombre o del espíritu-, cuyo carácter de cientificidad no ha dejado de estar en entredicho (López, 2005).

No se puede negar que el debate sigue presente, por tanto, para una mejor comprensión, se deben señalar algunas diferencias fundamentales entre ciencias naturales y ciencias humanas:

a) En cuanto a su objeto de estudio: las ciencias sociales se ocupan de la especie humana y su inherente subjetividad. Es así que, los objetos de estudio de las ciencias sociales no dejan de constituirse en las diferentes organizaciones sociales (la equivalencia de los textos) resultado de la acción humana - y valga la aclaración, aunque no necesariamente se han de considerar en un diseño consciente del ser humano.

b) En cuanto al método: desde las ciencias sociales la realidad no llega a ser algo dado allá afuera, un conjunto de hechos en bruto más o menos accesibles y que se encuentran disponibles a una teoría que busca describirlos y explicarlos, $y$, que procede a modificarlos o transformarlos de acuerdo con las necesidades económicas y sociales. De tal suerte, el sentido de la acción o, mejor dicho, el patrón significativo de la acción que la ciencia social ha de buscar comprender no podría ser considerado de carácter subjetivo ni objetivo (en el puro sentido fisicalista del término) y en consecuencia, se ha considerar un gran error pretender ajustar la investigación científica aplicada al hombre y a la sociedad al método científico propio de las ciencias naturales.

c) En cuanto al carácter del método: bien se sabe que el carácter de la metodología de las ciencias sociales ha de ser principalmente cualitativo, no obstante, por momentos y según las exigencias, podría llegar a ser mixto, es decir, cualitativo y cuantitativo. 
d) No busca regularidades o leyes: su objeto de estudio -la sociedad y sus individuos, sus acciones, sus instituciones, etc.- no se puede reducir a un hecho simpliciter, es decir, en bruto, no es posible hablar allí en términos de leyes o regularidades, pues, el ser humano, además de ser un ente biológico, es un ser psicológico, un ser social y un ser cultural, por tanto, irreducible a cualquier tipo de regularidad positivista, naturalista o fisicalista estricta.

e) La subjetividad del investigador: es un hecho que en la investigación de las ciencias sociales siempre se tiene que considerar la intervención de la subjetividad propia del investigador, definida por su biografía cultural y sus valores particulares. Es decir, la objetividad de las ciencias sociales tiene que considerarse indisolublemente vinculada a la subjetividad de sus investigadores (López, 2005).

\section{La objetividad y la subjetividad: la imposibilidad de un saber sin supuestos y un conocimiento sin historia}

A la luz de los anteriores criterios sobre el carácter de cientificidad de las ciencias sociales, y no obstante, sus críticas contra las posiciones que pretenden asentarse en un cientifismo acrítico y dogmático, para Ricœur, las ciencias sociales tienen asegurada su objetividad toda vez que, en el sentido epistemológico más estricto, se constituyen en un ejercicio del pensamiento con un carácter metódico, ordenado, comprensivo y comprensible de la misma manera que lo hacen las ciencias físicas y las ciencias biológicas. Empero, aclara, su objetividad tiene que llegar a definirse en términos de sus campos de estudio específicos, es decir, desde sus propias ontologías regionales. (López, 2005:165).

Debe entenderse que la objetividad de las ciencias humanas se encuentra ligada a la subjetividad del investigador social que busca indagar por el quehacer humano, e igualmente, a la subjetividad del otro -a la otredad del otro- en un amplio sentido del término. Justamente, para que esa comprensión de sí se alcance, se ha visto en la necesidad de asumir que: "La acción tendría que ser asimismo considerada como un texto" (Ricoeur, 2000: 169-195) y, como tal, puede ser interpretada ${ }^{2}$. En consecuencia, considera que la acción humana es esencialmente significativa y en la que, por definición, la acción es intencional, teleológica o pretende un propósito, a diferencia de los sistemas puramente físicos estudiados por las ciencias naturales. En ese caso, la acción significativa puede ser objeto de "ciencia", siempre y cuando el sentido de la acción pueda llegar a ser "objetivado" de una forma equivalente a como el sentido del discurso es plasmado por "escrito". En otras palabras, solamente si la acción puede ser vista apropiadamente como un análogo del texto -un cuasi-texto-, esta podría constituirse en objeto de la interpretación hermenéutica (Ricoeur, 1981: 206) y por tanto, objeto de las ciencias sociales y humanas. Aunque, reconoce que si bien son solo los individuos quienes hacen cosas; también se debe considerar que la acción humana se torna significativa y por tanto, comprensible y objeto de interpretación, solo en el ámbito de un mundo público compartido.

En efecto, todo este proceso de indagación ha de llevar a los investigadores sociales a encontrarse con "un mundo de la vida" que su propia novedad o diferencia no dejará de poner en entredicho o de retar sus propias presuposiciones; es decir, este cara-a-cara con este mundo ha de exigir la propia afectación, el propio cambio de quien investiga. En consecuencia, el proceso de interpretación ha de permitir alcanzar una comprensión del otro a través de relacionar el propio horizonte con el horizonte ajeno en una fusión de horizontes que, al exigir la expansión del propio, conduce a una suerte de renovación de sí. No es otro el paradigma de la intersubjetividad que ha de operar en este enfoque hermenéutico-fenomenológico (Wakefield, pág. 143). Es así que concuerda con Charles Taylor cuando asevera que la ciencia social trata con sentidos que no son subjetivos, es decir, que no residen en la cabeza de los actores; sino, con sentidos intersubjetivos. Taylor dice:

2. Para Ricœur, los elementos que permiten considerar al texto como un buen paradigma para comprender la acción humana son los siguientes: $a$ ) la acción humana es un cuasi texto: está exteriorizada de manera comparable a la fijación característica del discurso en la escritura; $b$ ) al desprenderse del agente, la acción adquiere una autonomía similar a la autonomía semántica del texto: deja un trazo, una marca, se inscribe en el curso de las cosas y se vuelve archivo y documento; $c$ ) el peso de la acción humana no se reduce a su importancia en la situación inicial de su aparición, sino que permite la reinscripción en nuevos contextos; $d$ ) es una obra abierta, dirigida a una sucesión indefinida de posibles lectores: los jueces que no serán los contemporáneos del agente, sino la historia ulterior. Ibíd. pp.175 - 182 
Los sentidos y las normas implícitas en las prácticas no solo se encuentran en las mentes de los actores, sino que están en las prácticas mismas, prácticas que no puede ser concebidas solamente como un conjunto de acciones individuales, sino que han llegado a ser formas de relación social, de acción mutua. (Taylor, 1979: 48)

En esta instancia, se debe considerar que, para el filósofo francés, el verdadero referente de un texto no es sino eso de lo que trata, es decir, no significa una realidad empírica sino una comprensión particular del mundo (Ricoeur, 1981). El sentido pretendido del texto es el mundo que este despliega, la proyección de un mundo es el proceso que se encuentra operando en el texto (Ricoeur, 1981). De hecho, no hay texto que no exprese un "mundo", que no conecte con una realidad, sin importar qué tan ficticio pueda ser este (Ricoeur, 1981). En cualquier caso, lo que ha querido dar a entender con la noción de "mundo del texto" no es otra cosa que el "mundo de la vida" de Husserl o el "ser-en-el-mundo" de Heidegger. Es decir, el "mundo posible" que se despliega en un texto no es otra cosa que "un posible modo de ser". Es un mundo que yo, el investigador, he de poder (probablemente) habitar. De tal suerte que, el texto, al abrirnos un mundo, nos ofrece nuevas dimensiones de nuestro ser-en-el-mundo (Ricoeur, 1981); nos sugiere formas diferentes y novedosas en las que podríamos llegar a ser o llegar a constituirnos. En ese sentido, se debe reconocer que, a su vez, este mismo proceso: "Nos hace evidente nuestra propia situación" (Ricoeur, 1981: 202).

No obstante, para el filósofo francés, su posición no deja de estar atenta en evitar caer en posiciones ingenuas a través de la apelación a un talante crítico que lo previene de la tentación del sentido inmediato. Así, el papel de la interpretación tiene que ser necesariamente crítico, puesto que, siempre existe, de un modo u otro, una cierta discrepancia entre lo que hace la gente y lo que la gente misma dice que hace. La crítica es una parte fundamental de la comprensión interpretativa en tanto función emancipadora. De tal suerte, la hermenéutica apela a la ficción y a la imaginación productiva como instrumento crítico con el que los individuos pueden alcanzar una transformación de sí y de su entorno, y por ende, crear nuevas formas de ser-en-el-mundo.
En consecuencia, el hecho de que seamos el resultado de, y nos encontremos afectados por, la historia, no debe tomarse en un sentido pasivo. Por el contrario, el pasado ha de recibirse de manera activa y debemos estar siempre dispuestos a su continua reinterpretación. En efecto, si por tradición hemos de entender también transmisión, es decir, la mediación activa que atraviesa la distancia temporal que nos separa del pasado, dicha transmisión ha de generar siempre sentidos nuevos. Por ello, hace énfasis en que: "El problema que plantea la historia -y agregaría, las demás ciencias sociales- es muy semejante al de la interpretación de un texto [...] En ambos casos la situación es la misma: no hay transmisión sin recepción activa y transformadora" (Ricoeur, 2009: 59). Para Ricœur, no podemos olvidar que la cuestión fundamental tiene que ser siempre interpretar críticamente el pasado y no, simplemente, aceptarlo. Entre otras razones porque no se nos ofrece al margen de los relatos que lo constituyen, ni al margen de sus diferentes interpretaciones.

Para él, el hecho inevitable de este asunto es que las ciencias humanas son "doblemente interpretativas"; estas llegan a constituirse en interpretaciones de las interpretaciones que las personas mismas han hecho de sus propias acciones. Y de tal suerte, concuerda con Clifford Geertz cuando sostiene que: "Lo que llamamos nuestra información es realmente nuestra propia construcción de las construcciones de otras personas de lo que ellos y sus compatriotas son y han sido capaces". (Geertz, 1973: 9).

Tomando pues la historia como ejemplo, Ricœur señala la objetividad de esta como "incompleta" en relación con otras ciencias sociales (López, 2005). Al respecto señala varias razones que buscan justificar esta aseveración:

a) En cuanto a la elección del objeto de estudio: para Ricœur, la decisión de estudiar tal o cual hecho histórico o suma de acontecimientos desde cierto punto de vista o perspectiva, ya se constituye en una evidencia de la intervención de los intereses e inclinaciones subjetivas del investigador. 
b) La concepción de causalidad: para Ricœur, la historia no deja de ser aún tributaria de un sentido ingenuo de causalidad que no logra superar la oscilación entre el determinismo y la probabilidad, llevándola al empleo de varios esquemas de explicación que no han logrado ser previamente distinguidos ni suficientemente reflexionados (López, 2005: 166).

c) La carga subjetiva del investigador: para Ricœur, el investigador de la historia, al aproximarse a su ejercicio, no puede desprenderse de su propia carga subjetiva e historia biográfica. Por tanto, al buscar reconstruir los hechos pasados desde su propia subjetividad genera toda una serie de grados de complicación dada la distancia temporal que pueda existir entre este y el objeto de estudio. Así, la distancia histórica ha de remitir, necesariamente, a la distancia cultural, lo que significa, a su vez, una evidente y complicada distancia simbólica. En ese sentido, afirma el filósofo francés que el lenguaje histórico no deja de ser necesariamente "equívoco" (López, 2005: 166).

d) La empatía del investigador con su objeto de estudio: considera Ricœur que un rasgo inevitable de la investigación histórica, a partir del propio involucramiento de la subjetividad del investigador, es la empatía, positiva o negativa, que pueda tener lugar en toda investigación de este tipo (López, 2005: 166-167).

Ahora bien, para Ricœur, a partir de estos factores, se podrían considerar dos formas de subjetividad, una positiva y una negativa. En primer lugar, la subjetividad positiva llega a constituirse o alcanzarse en un investigador social que se mantiene alerta ante su propio pathos, temple o condición de ánimo, es decir, frente a su propia afectación emocional en relación con su objeto de estudio. En ese sentido, considera que la phronesis, o sabiduría práctica del investigador, tendría que guiarlo para evitarle sucumbir en rencores, seducciones o silencios cómplices, etc., en relación con su objeto de estudio. En segundo lugar, la subjetividad negativa tendría que constituirse, necesariamente, en todo lo contrario de la anteriormente reseñada. Es así que, para Beltrán López,

Aplicar una buena subjetividad es una obligación de todo investigador social que se precie de ser científico, y en ello la reflexión filosófica tiene un papel fundamental, pues es ella la que nos asegura constantemente que el objeto de la investigación sea el mismo sujeto humano en su conjunto y no solamente las estructuras, las fuerzas o las instituciones, como lo consideran las posturas positivistas desde una perspectiva reduccionista (López, 2005: 167).

En definitiva, para Ricœur, en investigación social, la objetividad no deja de encontrarse necesariamente vinculada con la subjetividad que, sin sacrificar su investidura lógica, asume un carácter ético, moral y político (López, 2005). En consecuencia, exige de cualquier empresa hermenéutica la inclusión, en alguno de sus estadios, de un fuerte ejercicio "hermenéutico crítico". Considera, pues, que no hay asunto y ámbito en la actividad humana que sean por completo neutros, políticamente hablando: recreación, educación, artes, ciencia, toda dimensión de la vida humana es esencialmente política.

\section{Ciencia, científicos y expertos vs ciudadanos: a merced de la expertitis, la expertofrenia y la expertocracia}

A partir de lo anterior, el filósofo francés habrá de sugerir estar críticamente atento a cualquier historia de la filosofía o cualquier sistema de pensamiento que pretenda asumir encontrar una única verdad simple $\mathrm{y}$ arquitectónica sobre la humanidad y su forma de ser en el mundo, pues no deja de constituirse en una fuente que genere cualquier tipo de ejercicio de violencia sobre las personas. Para este, el hegelianismo sistemático, el marxismo científico, el catolicismo integrista, el objetivismo, positivismo, fisicalismo naturalista reduccionista, entre muchos otros, son falsificaciones peligrosas. Los sujetos pueden admitir, en cambio, que el orden de las ciencias sociales y humanas es ambiguo, que hay múltiples órdenes irreductibles de verdad, y que la experiencia humana revela un interminable juego 
dialéctico de la percepción, el conocimiento y la acción. Cualesquiera sean los argumentos que los sujetos tengan sobre el cuerpo de conocimiento de estas diferentes ciencias, estos deben ser reconocidos como probables.

En esta instancia, Ricœur sugiere estar críticamente atento contra las exclusiones sutiles y perjudiciales que han llevado a la exaltación que el mundo de hoy hace de toda esa serie de saberes y sus representantes -los llamados "expertos", su "expertofrenia" $y$ su "expertocracia”- que han de pretender crear sujetos eficientes pero, políticamente atrofiados y que propenden por ubicar en un segundo plano la participación de los demás ciudadanos. A través de sus reflexiones, advierte que la complejidad del mundo actual ha conducido a la tentación de insistir en que las voces de aquellos considerados “expertos" son las únicas que realmente importan en la determinación de políticas y prácticas que impactan y afectan a todos. Por ejemplo, en la relación médico-paciente, legislador-ciudadano, representante-representado, profesor-alumno, periodista-espectador, etc. En ese sentido, si bien, los Estados tienen la responsabilidad de establecer y mantener maneras institucionalizadas que aseguren los análisis y propuestas de los considerados "expertos" en muchas de las principales áreas tales como el derecho, la ética, la educación, la salud, la defensa, la economía y la comunicación; de igual forma, los Estados también son responsables de ofrecer las mediaciones institucionalizadas que permitan que los ciudadanos puedan acceder a la información de los llamados "expertos", de forma tal que la sociedad civil pueda reaccionar razonablemente a esta.

Al Estado, entonces, le compete la obligación de ofrecer la información suficiente para que los ciudadanos se puedan asegurar un examen justo e informado de los asuntos en discusión. Por ejemplo, al dar espacio para que sean escuchados voceros de organizaciones independientes, sociales y no gubernamentales, entre otras. Al mismo tiempo, es responsabilidad de los ciudadanos disponer de la mejor manera posible de los recursos ofrecidos $\mathrm{y}$ hacer que su participación en la vida política sea lo más sensata y prudente que se pueda. En este aspecto, piensa que toda democracia requiere de un Estado constitucionalmente activo y, al mismo tiempo, de una sociedad civil rica y diversificada como lo "Otro" del Estado. Así, la política apropiada no puede ser otra que la que comprende múltiples esferas que determinan los roles de los ciudadanos, sus derechos y sus obligaciones. Para Ricœur, todo Estado democrático necesita una sociedad civil fuerte y ello se hace más claro en los asuntos de la educación de sus futuros ciudadanos.

En efecto, afirma Ricœur, los agentes capaces no se constituyen en simples egos trascendentales ni en voluntades auto-suficientes y autónomas. Por ello, hace énfasis en que la capacidad humana se encuentra definida en gran medida por su facultad receptiva $\mathrm{y}$, no menos, por sus capacidades $\mathrm{y}$ habilidades. Ello se debe a que, desde su percepción, los agentes/sufrientes no crean sentido ex nihilo. De hecho, el sentido surge de, y continuamente se encuentra influenciado por las historias sociales y las tradiciones culturales y artísticas. Estas historias y tradiciones no se constituyen en aparatos monolíticos y definitivos. Son sentidos siempre provisionales, y el "hombre capaz" se presenta como una síntesis viva de dos órdenes a los que pertenece por constitución propia: de una parte, es un "ser-en-proyecto" que, en íntima interacción con los otros agentes, está volcado intencionalmente a transformar el mundo práctico; de la otra, es un "ser-en-el-mundo" que, gracias a su corporalidad, inserta eficazmente esa intencionalidad en el curso de las cosas. Por ello, la puissance d'agir emerge precisamente en la articulación dinámica entre estos dos órdenes, y esta conjunción establece al hombre en su capacidad ética y política. (Casarotti, 2008).

Por consiguiente, sostiene que una explicación de la subjetividad del investigador, en términos de capacidad humana, tiene que concebir el sí mismo como encarnado e incrustado en el tejido de las relaciones sociales. Las capacidades humanas emergen al sentido dentro del espacio público de las historias sociales, las realidades culturales y las tradiciones de pensamiento. Estas exigencias apuntan al hecho inevitable de que la capacidad humana es un fenómeno público; la capacidad significativa y competente es vivida en las esferas sociales y políticas donde los sí mismos (los investigadores) ejercen el poder individualmente y en grupos. Este hecho, a su vez, plantea nuevamente la pregunta frente a las 
normas morales y los valores: ¿qué constituye el bien humano? ¿Cuál es la acción correcta? ¿Cuál es la naturaleza de la justicia? En cualquier caso, es en el ámbito de la práctica social y política donde la capacidad humana es experimentada concretamente como una preocupación ética, en tanto persona moral y políticamente responsable. (Dauenhauer, 1998).

En alguna medida, lo que ha buscado plantear en los ámbitos moral y político ya nos es familiar. Para este, hay un sinnúmero de razones para ser suspicaz y crítico frente a las presuntas hegemonías cerradas de las tradiciones de la racionalidad, y ello se debe a que estas llevan consigo un gran potencial para reprimir la iniciativa humana, en la medida en que tienden a pretender darle sentido a la existencia; un ejemplo de esto es el gran aparato en que se han constituido hoy día los medios masivos de comunicación y su capacidad de creación de sentido. Si hay una razón para temer a una concepción moralmente neutral de poder y a una resistencia auto-justificada, se debe a que la acción social y política tomaría, con mucha frecuencia, la forma de un gesto violento, y no más frecuentemente, la forma de una apasionada petición por la liberación humana y la justicia social.

Debido a ello, la reflexión filosófica, ética y moral debe ser un constante recordatorio y un reconocimiento de que los agentes son seres capaces de llegar a constituirse en un ímpetu por una preocupación ética; pero, también, el recordatorio y el reconocimiento de que hemos de llegar a ser seres capaces de las formas más inhumanas de violencia; y, por lo tanto, la necesidad para que se consideren crítica y reflexivamente los propios límites que constituyen a los individuos como agentes moralmente responsables (Wall, 2005). Cabe resaltar acá que, en relación con el hombre capaz, insiste Ricœur, se tiene que apreciar la multidimensional fragilidad que afecta todo lo ético, moral y político. De allí que sea necesario reflexionar sobre lo que se requiere para participar en estos ámbitos de manera apropiada, además de lo que exige la responsabilidad. En el fondo, se tiene que exigir que se respeten y se salvaguarden estos espacios como ámbitos frágiles de pensamiento y acción que, por su parte, no carecen de limitaciones. (Dauenhauer, 1998).

\section{Ideología y utopía vs crítica y convicción}

Desde su propia perspectiva, afirma Ricœur, el quehacer ético, moral y político está atravesado íntegramente por una fragilidad fundamental que no se puede eliminar y que tiene sus raíces en la misma condición humana, a saber: en las capacidades e incapacidades de la persona para actuar. En ese sentido, las personas capaces y obligadas a actuar son constitutivamente heterónomas pues, aunque sus incapacidades nunca aniquilan las capacidades, sí logran reducirlas y constreñirlas.

De todo el conjunto de incapacidades, algunas son constitutivas de la naturaleza humana y el mundo, dígase: enfermedades, envejecimiento, limitaciones físicas, etc.; en cambio, otras se han ido creando en el curso de las interacciones con los otros, por ejemplo, manipulación, intimidación, ideologización, discriminación y muchas más. También, existen otras que son infligidas por la institucionalidad política como, por ejemplo, las modalidades de desigual distribución del poder para actuar, más particularmente, las que resultan de las jerarquías de comando y autoridad que se encuentran en sociedades que, como las actuales, han propendido por hacer énfasis en la eficiencia y la competencia (Ricoeur, 1995).

De allí se puede colegir que la responsabilidad política básica consiste en corregir y compensar de la mejor manera posible las múltiples formas de distribución inequitativa del poder de actuar. Con todo, para el filósofo francés, la política misma seguirá siendo irremediablemente paradójica, y esa paradoja asume básicamente tres formas: En primera instancia, se presenta como un conflicto entre la forma y la fuerza en el establecimiento de la organización de una comunidad histórica para la toma de decisiones. Por un lado, un Estado instituye una constitución en la que especifica los derechos y deberes que garantizan la igualdad de los ciudadanos ante la ley y, asimismo, da forma a la voluntad de la comunidad a vivir conjuntamente en instituciones justas. Pero, por el otro, esta misma constitución también institucionaliza una amenaza de fuerza legalizada que podría ser aplicada a los ciudadanos y a los extranjeros. El poder estatal, entonces, no está instituido solamente para alcanzar un vivir bien en instituciones justas sino que 
también se constituye en un poder que trata con la muerte (Ricoeur, 1993). En tal afirmación se subraya que no se puede ignorar el hecho de que toda vida política está inevitablemente marcada por una lucha por prevalecer o retener el control en las relaciones de poder, una lucha por el dominio político.

Ahora bien, la paradoja política se presenta, en segunda instancia, en la división real entre los que gobiernan y los gobernados. Así, la potestad, de los que gobiernan, a ejercer ciertos niveles de dominación sobre sus gobernados, ha sido supuestamente otorgada por la autoridad de la comunidad heredada del establecimiento previo y legítimo de la sociedad. No obstante, siempre permanece abierta la pregunta por el fundamento de ese tipo de relación: ¿de dónde viene la autoridad de los que gobiernan para mantener dominio sobre los gobernados? A decir de Ricœur, para alcanzar una respuesta plausible al interrogante anterior, es responsabilidad de los políticos tratar de hacer el apropiado empalme entre la dominación $\mathrm{y}$ el poder de vivir juntos como ciudadanos en instituciones justas, en tanto es una tarea que exige la reflexión ético-moral sobre el carácter perdurable del poder (Ricoeur, 1990).

La paradoja también se presenta, en tercer lugar, en las relaciones que el ámbito de la política mantiene con otros ámbitos de la actividad humana, dígase, el económico, el social, el familiar, el laboral, entre otros. Constantemente surge la pregunta: ¿es hoy el Estado una totalidad que contiene los otros dominios o es solo uno de los muchos ámbitos? Al respecto, afirma, hoy día se espera que el Estado se conduzca como el todo pero, también, como una parte de ese todo. En efecto, el Estado se erige como la esfera que contiene otras esferas pero, por sí misma, se constituye solamente en una región dentro de una región más amplia: El Estado es tanto lo que contiene como lo que es contenido.

Las tres paradojas políticas señaladas equivalen a formas incongruentes que se presentan en las relaciones de autoridad. Sin embargo, ello no significa que no se pueda poner en práctica una política saludable y sensata pues, aunque el discurso político pueda ser -en sí mismo- frágil, éste puede y debe poner en práctica maneras adecuadas de lidiar con las paradojas políticas en todas sus formas.
Sin embargo, un aspecto que se no se puede pasar por alto es que la profundidad y la fragilidad de la política se pueden evidenciar en toda su dimensión en el "discurso". El discurso político es frágil porque contiene inevitablemente elementos ideológicos y utópicos que amenazan con tornarlo patológico y perjudicial. Y esto se hace evidente en los discursos políticos que buscan justificar formas particulares de autoridad política. Es más, el discurso político es frágil puesto que no puede alcanzar conclusiones incontrovertibles en relación con valores, prácticas y objetivos políticos. Todo discurso político es inherentemente retórico y por tanto, se constituye en la expresión de opiniones y gustos, más no, de un conocimiento definitivo o verdadero. El discurso político es frágil pues, a pesar de tener que abordar a conciencia el tema de la ley y su fuerza vinculante, no logra resolver la paradoja de forma definitiva. Desde su punto de vista, el discurso político tan solo puede conducir a una "sabiduría práctica" que nunca alcanza a convertirse en certeza (Dauenhauer, 1998).

Inherente a su tesis de la fragilidad de todo lo político, afirma Ricœur, se encuentran prácticas o discursos perjudicialmente ideológicos o utópicos, con el agravante de la imposibilidad de eliminarlos. No obstante, a través de la sabiduría práctica que propone, la presencia de tales elementos puede ser más benéfica que perjudicial y, ello, por la vía de la interminable dialéctica entre la crítica y la convicción. Es así que piensa que la ideología y la utopía son una expresión de la imaginación social y cultural constitutiva de cualquier sociedad perdurable. Si bien, la ideología y la utopía pueden tener efectos perjudiciales y destructivos en los ciudadanos, no son necesariamente patológicas sino que se pueden volver saludables y constructivas para la vida de una sociedad política, en tanto la salud de una exige la de la otra; y, también, la patología de una, regularmente, si no siempre, va de la mano con la de la otra (Ricoeur, 1986).

Sus reflexiones en este aspecto muestran cómo desde Marx, tanto la ideología como la utopía han sido entendidas peyorativamente. Es así que, desde su punto de vista, se ha asumido la ideología, fundamentalmente, como una forma equivocada $y$ peligrosa de responderle al mundo; y la utopía, con frecuencia, como una manera de escaparse de la 
realidad dura del mundo; es decir, como una fantasía o un sueño. En consecuencia, quien defienda una ideología o acepte una utopía será generalmente calificado de padecer una suerte de enfermedad política o social.

Así, en relación con esta acepción fundamentalmente peyorativa, sus análisis del concepto de ideología distinguen dos formas diferentes de definirla. En primer lugar, en el pensamiento temprano de Marx, la ideología es como una representación que hay que oponer a la realidad en la medida en que caracteriza de forma distorsionada las condiciones y efectos de la lucha de las personas por ganarse su sustento. Esta representación equivocada lleva a los individuos a la alienación en relación con su propia situación laboral y sus condiciones reales de vida. En segunda instancia, en el pensamiento maduro de Marx, la ideología se opone a la ciencia marxista pues, como esta última trata con la infraestructura de la sociedad, las relaciones de producción y las clases sociales en conflicto, cualquier preocupación humanista sobre las situaciones de vida de los individuos se constituirá, de tal suerte, en ideológica (falsa conciencia). Este cambio de acepción entre el primer y el segundo Marx, recalca, parece que no deja de ser del todo ideológico. Esta implicación caería, en lo que ha llamado "la paradoja de Mannheim". Veamos: "Si todo discurso es una expresión de prejuicios e intereses no reconocidos y, por tanto, es ideológico, ¿cómo puede el discurso marxista estar seguro de mantenerse libre de la infección ideológica?" (Dauenhauer, 1998: 214).

Para impedir la paradoja y, al mismo tiempo, rescatar parte del valor de la crítica marxista, Ricœur busca ubicar el concepto de ideología en un marco más amplio que permita reconocer la estructura simbólica de la existencia humana y, no exclusivamente, su carácter de disimulación o práctica distorsionadora de la realidad. Así, considera que toda acción humana genuina involucra una función simbólica que le adscribe un sentido y un ajuste a la acción de patrones completos de formas de vida. Ahora, ello no significa que esta estructura simbólica se encuentre a salvo de la producción de representaciones distorsionadas; solo afirma que estas perversiones nunca serán totales. Así pues, la función distorsionadora de la ideología nunca abarcará la totalidad de la imaginación social sino tan solo una pequeña parte.
En consecuencia, define el término "ideología" como un conjunto de estructuras simbólicas que constituye y cohesiona una comunidad identificable; sin estas estructuras simbólicas de cohesión, la comunidad humana no podría ser posible. De hecho, como toda acción humana se encuentra simbólicamente estructurada y organizada, las personas pueden ver la manera como las acciones de esta persona encajan tanto con una vida coherente como con una comunidad estable. Solo con la ayuda de tales estructuras simbólicas se podría entender cómo una persona o una comunidad alcanzan su integración e identidad. En otras palabras, la ideología no es fundamentalmente destructiva, antes bien, juega un papel constructivo en el establecimiento y mantenimiento de una comunidad humana.

La anterior definición se opone a la definición sostenida por Marx en sus primeros escritos, en los que asume la ideología como el resultado de intereses desconocidos que distorsionan el pensamiento y la praxis, y, que posibilita el establecimiento de un sistema de control que permite instaurar la diferenciación y la jerarquización en una comunidad.

De tal suerte, el objetivo de la ideología no podría ser otro que llenar, de la mejor manera posible, una cierta brecha de credibilidad que, de otra forma, carecería cualquier sistema de gobierno y sus gobernantes. Al respecto, señala que, a no ser por ciertos niveles de discursos ideológicos, la distinción entre los que gobiernan y los que son gobernados no se llegaría a encontrar en ninguna justificación de un contrato social que pueda ser determinado temporalmente, tal como lo sostenía Max Weber, sino que esta es hecha por unos y otros sobre la base de la relación entre la autoridad y la dominación que ya mantienen. Sin embargo, como los gobernantes no solo establecen y mantienen un orden a través de la fuerza, sino que también se otorgan las atribuciones de ser los designados para la tarea de gobernar, han de buscar obtener la cooperación y el consentimiento de sus gobernados, por medio del constante ejercicio discursivo de hacer que estos últimos asuman que la autoridad y la dominación del gobernante no han dejado de ser las correctas y las apropiadas. 
Es más, también siguiendo a Weber, piensa que ni hay ni habrá legitimación alguna de un sistema de gobierno que sea completamente racional. Es decir, no hay un conjunto de normas racionales y razonables que puedan determinar definitivamente $\mathrm{y}$, de una vez por todas, los que deben gobernar y el sistema de gobierno que debería adoptar una sociedad. Asimismo, difícilmente se podrían tener evidencias de una comunidad humana compleja que haya podido perdurar sin gobernantes y sin un sistema de gobierno. En ese sentido, tiene que haber alguna justificación dada para el hecho de que sea $\mathrm{X}$ y no algún $\mathrm{Y}$, quien gobierne, y para los sistemas que determinan quién es ese $X$. Pero, hay que tener en cuenta que las exigencias hechas sobre estos asuntos siempre exceden la evidencia disponible. Las alternativas son siempre posibles y algunas de estas son de hecho plausibles. (Dauenhauer, 1998).

Por tanto, como ya se afirmó con antelación, el objetivo de la ideología no es otro que llenar la brecha de credibilidad que se presenta entre el sinnúmero de exigencias que los gobernantes hacen a sus gobernados y las evidencias disponibles para convencer a los ciudadanos de la pertinencia de las exigencias y la necesidad de su aceptación. En otras palabras, a través de la ideología, como sistema de justificación, se preserva la comunidad creando un puente entre la necesidad racional de legitimar la autoridad y la dominación, y, la imposibilidad de los gobernantes y su sistema de gobierno para alcanzar una justificación definitiva. Sin la función de enlace de la ideología, sería prácticamente imposible ver cómo una comunidad numerosa y compleja pudiera existir, mucho menos, perdurar por un largo período de tiempo.

De cierto modo, la ideología afirma más de lo que realmente puede ofrecer en términos de evidencia; por tanto, es proclive a ser usada para distorsionar o disfrazar realidades. La ideología tiende inevitablemente a justificar un status quo o a canonizar un sistema de gobierno existente por medio de su función principal de establecer y preservar la identidad de una comunidad al buscar asegurarse su legitimidad y la aceptación de los ciudadanos. En sus propias palabras, ya lo había advertido, todo el potencial patológico de la ideología procede de su papel conservador. (Ricoeur, 1986).
Por otra parte, desde sus planteamientos, asevera Ricœur, el contrapeso dialéctico de la ideología en el funcionamiento de la imaginación cultural es la utopía en tanto se erige como un llamado de atención a los ciudadanos sobre la insuficiencia de la ideología para ofrecer evidencias justificadoras creíbles sobre la legitimidad de los gobernantes y su sistema de gobierno.

En consecuencia, considera que la imaginación cultural no solo funciona en la promoción de la integración y la estabilización de una comunidad determinada, sino que también instiga a sus ciudadanos a asumir posturas críticas frente a la vida ética, moral, social y política (Ricoeur, 1986). En este orden de ideas, establece una semejanza entre la función de la utopía y las variaciones imaginativas en la fenomenología de Husserl pero, esta vez, sobre realidades relacionadas con la vida intersubjetiva y comunitaria: la familia, la religión, el gobierno, y especialmente, el poder institucionalizado. Es decir, la utopía, en su función imaginativa, se encuentra proyectando, no de manera conservadora ni mucho menos integradora, particularmente, otro tipo de sociedad y, más ampliamente, un mundo diferente que no se ha constituido aún en una realidad presente. Así, la función crítica a la que la utopía somete un status quo sociopolítico, es decir, una crítica de lo que existe en el presente, no descansa en algo que ya tenga existencia actual sino que se constituye en un pensamiento que se ubica en una especie de "ninguna parte". Sin embargo, ello no significa que el pensamiento utópico carezca de puntos de referencia y sea mera fantasía; por el contrario, éste se refiere a una condición o un mundo que debería existir en cambio de aquel que ya existe (Dauenhauer, 1998).

La utopía, en su función imaginativa y crítica, pone en entredicho la aparente validez y legitimidad incontrovertible que un sistema de control se quiera atribuir a sí mismo, y propone vías alternativas para el ejercicio del poder en todos los ámbitos de la vida humana: lo familiar, la religión, lo económico, lo legal o la vida política; advirtiendo que estas vías posibles para ejercer el poder no buscan restaurar la violencia sino poner en marcha "otra sociedad" con un tipo diferente de ejercicio del poder que impere en una determinada espacio-temporalidad. 
Ahora bien, para Ricœur, tanto la ideología como la utopía pueden ser empleadas en formas patológicas. $\mathrm{Si}$ el pensamiento utópico quiere sobrepasar las situaciones actuales en sus variaciones imaginativas y entrar a considerar realidades en "ninguna parte", se hace proclive al "escapismo"; a la evaluación de la realidad, en términos de un "sueño" que pretende articular esquemas auto-contenidos de perfección radicalmente ligados al registro de la experiencia humana preocupada por lo que debería ser genuinamente digno. Al respecto, ha escrito que: "Este escapismo, bajo el disfraz de señalar un futuro paraíso a ser ganado, de hecho, disimula una nostalgia regresiva hacia algún paraíso perdido e imaginario" (Dauenhauer, 1998: 218). En consecuencia, la tendencia patológica de la utopía podría tomar dos vías:

Las utopías siempre deslegitiman la autoridad y el poder de dos maneras. Primero, las utopías podrían afirmar que no debería haber ningún poder institucional. Esta es la vía de la anarquía. Segundo, las utopías podrían afirmar que el poder debería ser re-institucionalizado de otra manera más racional. Aquí, solamente el mejor o los más sabios, como lo determina el criterio de la utopía, deben gobernar. Esta es la vía de la tiranía, quizás, un tirano benevolente, pero, un tirano al fin y al cabo (Dauenhauer, 1998: 219).

Entiéndase bien, estas tendencias patológicas no hacen que el pensamiento utópico se torne necesariamente malsano; antes bien, la idea es que estas limitaciones, a saber, el escapismo y el salto a "ninguna parte", se tornen precisamente en su fortaleza. Por tanto, la función de la utopía será retar al estatus quo, al introducir un elemento de duda o sospecha en el orden presente de las cosas. De tal suerte que, mientras la ideología trata de justificar una vida social y política existente, la utopía busca re-describirla y así mostrar que esta puede ser de otra manera (Dauenhauer, 1998).

Para que el pensamiento utópico pueda escapar de sus formas patológicas y se alcance a constituir en una herramienta terapéutica no puede, en realidad, estar ubicado en "ninguna parte", puesto que, si su esfuerzo no es otro que mostrar que la vida social y política podría ser de manera diferente a la presente, entonces, tiene que reconocer que su sentido y legitimidad dependen, al menos en parte, de esa realidad presente que critica. Además, la utopía también tiene que admitir que el sistema de gobierno que critica tiene fuerza y no carece de características mínimas de justificación; la utopía, entonces, tiene que considerar que ningún sistema de gobierno es malo por sí mismo y sin un juicio crítico previo.

En consecuencia, sostiene que la mayoría de utopías, si no todas, tiene su punto de partida en una noción de promesa que aún no ha sido cumplida, en una oportunidad real para alcanzar el bien pero que, por una u otra razón, no fue alcanzada (Dauenhauer, 1998).

En efecto, ha encontrado que en la vida social y política de nuestro tiempo, los pensamientos ideológicos y utópicos operan en los niveles de: (a) distorsión, (b) legitimación, y (c) formación de identidad (Dauenhauer, 1998). Se ve pues, cómo la ideología y la utopía pueden ser tanto incompatibles como compatibles y, ello, dependiendo del nivel donde se encuentren. En el nivel de la distorsión -el más superficial de todos- las funciones ideológicas y utópicas son simplemente incompatibles. Sin embargo, en los dos niveles siguientes, a saber, el de la legitimación y el de la formación de identidad, respectivamente, sus funciones pueden ser complementarias en tanto no se vuelvan patológicas.

Entonces, mientras la ideología funciona en la integración de la sociedad y busca asegurar su permanencia por la vía de la legitimación del sistema de control imperante y la educación de los nuevos miembros (niños, inmigrantes, etc.), en un sentido de comunidad; la utopía funciona al llamar la atención de los sujetos sobre el carácter prospectivo y retrospectivo de su identidad, manteniendo a los individuos y a los miembros de una comunidad abiertos a sus expectativas para un futuro nuevo y aún por llegar, evitando, además, la repetición de su pasado y su presente, como si no fuera posible ser pensado en otras opciones. Así que, la identidad se encuentra siempre, parcialmente, "en suspenso". 


\section{Conclusiones}

De todo lo anterior, se podría colegir que sus análisis sobre la ideología y la utopía tienen muchas implicaciones para la participación concreta de los individuos y las comunidades en el discurso y la acción política. En primer lugar, las funciones ideológicas y utópicas de la imaginación social son constitutivas tanto de los individuos como de las comunidades. En segundo lugar, las funciones ideológicas y utópicas de la imaginación social no se encuentran a salvo de sus formas patológicas.

Es cierto, también, que la ideología y la utopía se pueden constituir en una terapia que la vida social permanentemente requiere; incesantemente, se ha tenido que hacer uso de la función saludable de la ideología para curar a las comunidades de la locura de la utopía; asimismo, se ha tenido que hacer uso de la función crítica de la utopía para curar a las comunidades de la patología ideológica. Con todo, el uso terapéutico tanto de la ideología como de la utopía, por parte de una comunidad, no llega a ser nunca completamente transparente. Ninguna persona o grupo podría correctamente atribuirse ser el determinador de lo que debería ser una imaginación social saludable $\mathrm{y}$, por tanto, de lo que contaría como una conducta política sensata. Además, nadie puede afirmar tener inequívocamente el gran fundamento ético, moral y político al que los otros simplemente deberían adherirse. Igualmente, esta falta de transparencia no significa que la pasividad o la apatía política se encuentren justificadas sino que, por el contrario, esta sirve para mostrar que ningún ciudadano tiene razones para renunciar a sus completas responsabilidades para con los otros en la búsqueda de la supervivencia o el bienestar de la sociedad política.

Igualmente, ha encontrado que, en la vida política actual, los ciudadanos deberían tratar de transformar el círculo dialéctico entre la ideología y la utopía en una espiral ascendente que les ofrezca algo de esperanza en el mejoramiento personal y de sus conciudadanos. Pero, asimismo, debe asegurar que la única manera de lograrlo es que las personas se comprometan con algún conjunto de valores y vivan de acuerdo con éste. No obstante, insiste en la imposibilidad de alcanzar un punto de vista inclusivo en la vida social y su historia que, definitiva y completamente, elimine todas las patologías ideológicas y utópicas.

Por tanto, debe concluir que toda comunidad que pretenda determinar la concepción de vida sociopolítica que quiere mantener y sobre la que iría a actuar, se ve obligada a apelar al criterio de Mannheim de lo apropiado. De acuerdo con este criterio, lo valioso de cualquier concepción de la vida sociopolítica a la que se haya llegado a través del ejercicio de las funciones ideológicas y utópicas que constituyen la imaginación social, tendría que ser evaluado a través de su idoneidad para constituir la identidad de un grupo. De tal suerte, esta tendría que ser congruente con las exigencias de las condiciones específicas en las que la vida social tiene que ser vivida y las posibilidades benignas que estas condiciones posibilitan. Si bien, debe confesar que este criterio es muy difícil de aplicar, no ha logrado llegar a una alternativa que sea más sensata y evidente para ello.

En síntesis, desde su punto de vista, los miembros de una sociedad determinada podrían razonablemente alcanzar una relativa legitimidad para sus estructuras de autoridad, si apelan a la "sabiduría práctica" como un medio para preservar la relación dialéctica existente, tanto entre la ideología y utopía como entre la crítica y la convicción. Mientras esto se haga por largo tiempo, la comunidad puede preservar una razonable identidad pública, social y política e, igualmente, mantenerse dentro de límites seguros frente a la siempre presente incitación de la distorsión ideológica y utópica como bien se mostraba anteriormente en relación con el cientifismo. No se puede olvidar que no solo la reconciliación sino las expectativas han de abrir otras posibilidades hacia el futuro; la posibilidad de una construcción futura de alternativas que dé lugar al cumplimiento de las promesas. No obstante, ello no debilita, en nada, la necesidad de estar críticamente atentos contra las exclusiones sutiles y perjudiciales de toda esa serie de saberes y sus representantes -los llamados "expertos" - que han propendido por ubicar en un segundo plano la participación de los demás ciudadanos. En esta instancia, se debe reiterar que, para el filósofo francés, todo Estado democrático vigoroso y dinámico exige una sociedad civil crítica, fuerte y saludable como salvaguarda de la intencionalidad ética de vivir bien con y para los otros en instituciones justas. 


\section{Referencias bibliográficas}

Casarotti, E. (2008). Paul Ricoer: Una antropología del hombre capaz. Argentina : Educc.

Dauenhauer, B. P. (1998). Paul Ricoeur: The Promise and Risk of Politics. England: Rowman and Little Filed Publishers.

Geertz, C. (1973). The Interpretation of Culture. New York: Basic Books.

Hengel, J. W. (1982). The Home of Meaning: The Hermeneutics of the Subject of Paul Ricoeur. Washington D.C: University Press of America.

López, D. B. (2005). Objetividad y subjetividad en las Ciencias Sociales. El caso de la Historia en la reflexión de Paul Ricoeur. Clio, 159-160.

Mardones, J. (1991). Filosofia de las ciencias humanas y sociales. Materiales para una fundamentación científica. México: Anthropos.

Ricoeur, P. (1981). Hermeneutics and the Human Sciences. New York: Cambridge University Press.

Ricoeur, P. (1986). Lectures on Ideology and Utopia. New York: Columbia University Press.

Ricoeur, P. (1990). Ethics and Politics en: Ricoeur, Paul, lectures I. Autor du politique. Le Seuil

Ricoeur, P. (1993). Morale, éthique et politique en Pouvoirs, Revue francaise d'etudes constitutionnelles et politiques.

Ricoeur, P. (1995). Autonomie et vulnérabilité Séance inaugurale du Séminaire de l'IHEI .

Ricoeur, P. (1995). Le Juste . Paris: Esprit.

Ricoeur, P. (2000). Del texto a la acción II. México: Fondo de cultura económica.
Ricoeur, P. (2006). Sí mismo como otro. Madrid : Siglo XXI.

Ricoeur, P. (2009). Educación y política: de la historia personal a la comunión de libertades. Buenos Aires: Prometeo .

Simms, K. (1995). Paul Ricoeur. Londres : Routledge.

Taylor, C. (1979). Interpretation and the Sciences of Man In: Interpretive Social Science: A Reader. Berkeley: University of California Press.

Wall, J. (2005). Moral Creativity: Paul Ricoeur and the Poetics of Possibility. New York: Oxford University Press. 